\title{
Prior Exposure to Chronic Stress Results in Enhanced Synthesis and Release of Hippocampal Norepinephrine in Response to a Novel Stressor
}

\author{
Laura K. Nisenbaum, Michael J. Zigmond, Alan F. Sved, and Elizabeth D. Abercrombie \\ Department of Behavioral Neuroscience, University of Pittsburgh, Pittsburgh, Pennsylvania 15260
}

The release and synthesis of norepinephrine (NE) in hippocampus were measured in naive and chronically coldstressed rats in response to acute tail-shock stress. Using in vivo microdialysis, it was determined that the basal extracellular concentrations of NE and 3,4-dihydroxyphenylacetic acid (DOPAC) in hippocampus were the same in the two groups. However, $\mathbf{3 0}$ min of intermittent tail shock produced a greater elevation of extracellular NE and 3,4-dihydroxyphenylacetic acid in the chronically cold-stressed rats than in the naive controls. In hippocampus, the extracellular concentration of DOPAC may reflect NE biosynthesis, and thus the enhanced DOPAC response in the chronically stressed rats suggests an increase in NE synthesis. In order to investigate this possibility, two further methods of assessing NE biosynthesis were employed. Tyrosine hydroxylase (TH) activity was assayed in vitro in the presence of saturating concentrations of cofactor. No change in maximal TH activity could be detected in hippocampus of chronically cold-stressed rats. In addition, the in vivo rate of tyrosine hydroxylation in cold-stressed rats was measured by the accumulation of 3,4-dihydroxyphenylalanine in tissue following inhibition of aromatic amino acid decarboxylase. It was found that, whereas basal synthesis was the same in both groups of rats, synthesis accompanying a novel stressor was increased to a greater extent in the chronically stressed rats.

The noradrenergic neurons of the locus coeruleus (LC) have been implicated in the response of the CNS to environmental stressors. For example, stressful stimuli elicit an increase in the firing rate of LC neurons (Abercrombie and Jacobs, 1987) and an elevation in norepinephrine (NE) turnover in the forebrain (Thierry et al., 1968; Korf et al., 1973; Tanaka et al., 1983). Moreover, severe stress reduces the NE content of brain tissue (Maynert and Levi, 1964; Zigmond and Harvey, 1970; Weiss

Received Sept. 12, 1990; revised Nov. 27, 1990; accepted Dec. 21, 1990.

These data were presented, in part, at the 1989 and 1990 Annual Meetings of the Society for Neuroscience. This research was funded in part by U.S. Public Health Service Grants MH43947 (M.J.Z., E.D.A.), MH09658 (E.D.A.), and MH 18273 (L.K.N.), by the National Alliance for Research on Schizophrenia and Depression (E.D.A.), and by the American Heart Association (A.F.S.). We thank Jen-Shew Yen for histological preparations.

Correspondence should be addressed to Laura K. Nisenbaum, Department of Behavioral Neuroscience, University of Pittsburgh, Pittsburgh, PA 15260.

- Present address: Center for Molecular and Behavioral Neuroscience, Rutgers University, Newark, NJ 07102.

Copyright (C) 1991 Society for Neuroscience $0270-6474 / 91 / 111478-07 \$ 03.00 / 0$ et al., 1976; Tsuda et al., 1982; Glavin et al., 1983). These changes presumably reflect enhanced release of $\mathrm{NE}$ in response to acute stress. In addition, an increase in NE biosynthesis is thought to occur. It has been demonstrated that presentation of a stressful stimulus can result in a rapid but short-term increase in the activity of the rate-limiting enzyme tyrosine hydroxylase (TH; Iuvone and Dunn, 1986) and an increase in the extracellular concentration of NE in hippocampus (Abercrombie et al., 1988; Kalen et al., 1989), a region receiving noradrenergic innervation from $\mathrm{LC}$.

In response to more prolonged demand, further alterations in the utilization of NE have been observed. For example, prior exposure to chronic stress can result in an enhancement of stressinduced increases in NE turnover (Thierry et al., 1968; Kvetnansky et al., 1983). Previous exposure to repeated stress also can protect against depletions of central NE tissue levels induced by acute stress (Zigmond and Harvey, 1970; Weiss et al., 1976; Ritter and Ritter, 1977). Moreover, chronic stress has been shown to result in an elevation of the tissue level of central NE (Irwin et al., 1986; Adell et al., 1988). These effects of chronic stress may indicate an increase in the biosynthetic capacity of noradrenergic neurons. Indeed, a prolonged increase in the $V_{\max }$ for $\mathrm{TH}$ has been demonstrated in LC neurons in response to various chronic stressors, including chronic cold and foot-shock stress (Thoenen, 1970; Zigmond et al.; 1974; Stone et al., 1978; Richard et al., 1988). This type of long-term increase in enzyme activity has been shown to reflect an induction of new TH protein biosynthesis (Joh et al., 1973; Chuang and Costa, 1974). Studies such as these that investigate changes in TH produced by chronic stress, however, have focused on the cell bodies of LC neurons, and thus the functional consequences of chronic stress-induced changes at the terminal level remain unclear.

Although an increase in NE utilization following prior exposure to chronic stress is suggestive of an increase in NE synthesis and release, it is difficult to infer changes in release from changes in the tissue levels of NE or its metabolites. For example, we have demonstrated that changes in the extracellular concentration of a neurotransmitter do not necessarily coincide with alterations in tissue neurotransmitter levels (Abercrombie et al., 1989). Moreover, changes in metabolite levels may reflect alterations in the metabolism of intracellular as well as extracellular NE (Badoer et al., 1989). Therefore, in order to measure more directly NE output, in vivo microdialysis was employed to quantify extracellular NE within hippocampus of naive and chronically cold-stressed rats under basal conditions as well as in response to a subsequent novel stressor. In addition, NE 
biosynthesis was assessed both in vitro and in vivo to determine whether any stress-induced changes in this variable had occurred.

\section{Materials and Methods}

\section{Animals}

Male Sprague-Dawley rats (Zivic-Miller Laboratory, Pittsburgh, PA) weighing $300-400 \mathrm{gm}$ at the time of study were used. Rats were housed two per cage in a temperature-controlled room $\left(22-23^{\circ} \mathrm{C}\right)$ on a $12: 12-$ $\mathrm{hr}$ light/dark cycle for at least 1 week prior to the beginning of all experiments. Food and water were available ad libitum.

\section{Stress procedures}

Chronic stress. Rats assigned to the chronic cold-stress group were shaved and placed immediately into a cold room (ambient temperature, $5^{\circ} \mathrm{C}$ ), where they were housed singly for 3-4 weeks. Control rats were not shaved and remained in their home cages. Cold exposure was chosen as the chronic stressor because it has been shown that this stimulus produces an increase in TH activity within the cell bodies of LC neurons (Thoenen, 1970; Zigmond et al., 1974; Richard et al., 1988). We previously have shown that placing rats in the cold unshaven or providing nesting material attenuates cold-induced increases in TH activity in the autonomic nervous system (Fluharty et al., 1983). Therefore, in order to prevent behavioral adaptation, rats were housed singly and without nesting materials during the cold-stress period.

Acute stress. Intermittent tail shock was administered through a cuff containing two stainless-steel contact electrodes on opposite sides of the rat's tail. The shock consisted of constant current pulses at $1.0-\mathrm{mA}$ intensity delivered for $1 \mathrm{sec}$ every $10 \mathrm{sec}$ for a duration of $1 \mathrm{~min}$. This procedure was repeated every $5 \mathrm{~min}$ for $30 \mathrm{~min}$ (total of 30 pulses).

\section{Dialysis probe calibration}

Two types of dialysis probes were used in these experiments. Included in this study are data from five rats in the control group and three in the experimental group using a loop-style dialysis probe measuring 5 $\mathrm{mm}$ in total loop length (Abercrombie et al., 1988). In addition, data from four control and six experimental rats were obtained with a vertical concentric-style dialysis probe measuring $2.5 \mathrm{~mm}$ in length (Abercrombie et al., 1989). All dialysis probes were calibrated for relative recovery rate prior to implantation by placing them in a beaker containing artificial cerebrospinal fluid (CSF; composition: $147 \mathrm{mM} \mathrm{NaCl}, 2.71 \mathrm{~mm}$ $\mathrm{KCl}, 1.22 \mathrm{~mm} \mathrm{CaCl}, \mathrm{pH}$ 7.4) to which NE and DOPAC standards had been added $\left(5 \times 10^{-8} \mathrm{M}\right)$. The artificial CSF was continuously perfused through the probe at $1.75 \mu \mathrm{l} / \mathrm{min}$ by a microliter infusion pump (Harvard Pump 22). The concentration of NE and DOPAC in perfusate obtained from the dialysis probe was quantified and compared to that in the beaker. The mean relative recovery rate of NE was $23.1 \pm 1.4 \%$ for loop-style and $9.6 \pm 0.7 \%$ for vertical concentric probes. There was no significant difference between the two styles of dialysis probes when basal NE and DOPAC values were compared after correction for in vitro recovery (NE: $t=0.13, p>0.05$; DOPAC: $t=0.23, p>0.05$, respectively). Data collected with both types of dialysis probes therefore were combined.

\section{Dialysis probe implantation and sample collection}

Probes were implanted stereotaxically into the dentate gyrus of dorsal hippocampus under equithesin anesthesia $(3.0 \mathrm{ml} / \mathrm{kg}$, i.p. $)$ at the following coordinates relative to bregma and dura: $\mathrm{AP},-3.8 ; \mathrm{ML}, \pm 2.0$; DV, -3.8 (for details, see Abercrombie et al., 1988). After implantation of the dialysis probe, the rat was allowed to recover from surgery overnight. Before initiating the experimental manipulation, neurotransmitter efflux was monitored for a minimum of $1 \mathrm{hr}$ in order to ensure stable baseline values (defined as four samples in which NE levels varied by less than 10\%). At the beginning of the intermittent tail-shock paradigm, a 5-min delay in sample collection was introduced to correct for the time required for the artificial CSF to travel from the brain to the collection vial. After completion of each experiment, rats were perfused intracardially with $10 \%$ formalin. The brain was removed, sectioned, stained with Luxol fast blue and Safranin-O, and examined for probe placement. If the probe track was located outside of the dentate gyrus region of hippocampus, the data were discarded.

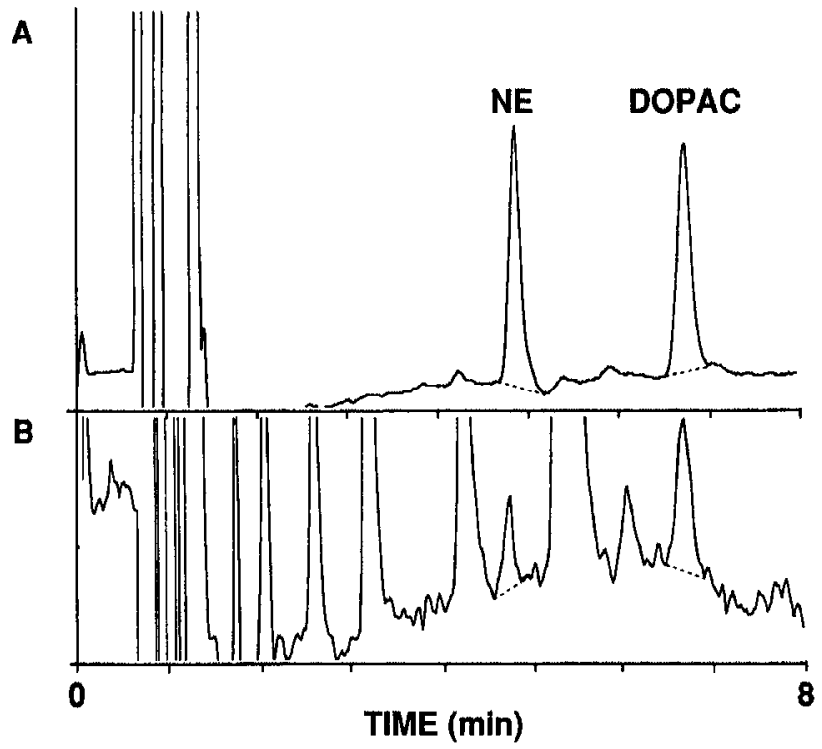

Figure 1. Chromatograms obtained from $20 \mu \mathrm{l}$ of a standard solution containing $34 \mathrm{pg}$ NE and $36 \mathrm{pg}$ DOPAC $(A)$ and from $20 \mu \mathrm{l}$ of hippocampal dialysate containing $0.96 \mathrm{pg} N E$ and $1.68 \mathrm{pg}$ DOPAC $(B)$. The amplification of the detector output signal for the hippocampal dialysate is 13-fold greater than that for the standard solution.

\section{NE and DOPAC quantification}

Quantification of the amount of NE and DOPAC in the dialysates was accomplished on a liquid chromatographic system with minor modification of previously described methods (Abercrombie et al., 1988). Briefly, the dialysate was injected directly onto the HPLC consisting of a Waters 510 Solvent Delivery System, a Rheodyne 9125 injector, and a Velosep RP-18 column $(100 \times 3.2 \mathrm{~mm}, 3 \mu \mathrm{m}$; Brownlee Labs). The mobile phase contained 80 mM sodium phosphate buffer $(\mathrm{pH}, 2.75)$, $100 \mu \mathrm{M}$ EDTA, $1.16 \mathrm{~mm}$ sodium octyl-sulfate, and $4 \% \mathrm{v} / \mathrm{v}$ methanol. The flow rate was $700 \mu \mathrm{V} / \mathrm{min}$. The detection system was an ESA $5100 \mathrm{~A}$ electrochemical detector with three electrodes in series. The first was a conditioning electrode with the applied potential set at $+0.26 \mathrm{~V}$. The applied potential of the second electrode was set at $-0.21 \mathrm{~V}$, and the third electrode, at which the compounds of interest were quantified, was set at $+0.21 \mathrm{~V}$. Peak heights were measured and compared to peak heights of standards. The sensitivity of this assay is $0.5-1.0 \mathrm{pg}$ of NE. $\mathrm{NE}$ and DOPAC were expressed as picograms per $20 \mu \mathrm{l}$ of dialysate, corrected for relative recovery of the probe. A typical chromatogram obtained from a dialysis sample is shown in Figure 1.

\section{Tyrosine hydroxylase activity assay}

Rats were killed by decapitation, and the brain and adrenal glands were removed and placed on ice. The adrenal glands were dissected free of fat, and brainstem and hippocampus were dissected out. All structures were frozen immediately on dry ice. The brainstem then was placed in a cryostat, and a 1-mm coronal section of the pons was cut at the level of the LC. With the aid of a dissecting microscope, LC was visualized, and a $1-\mathrm{mm}$ punch of tissue was taken bilaterally. All tissues were stored at $-70^{\circ} \mathrm{C}$ prior to assay. Soluble $\mathrm{TH}$ activity was assayed by a modification of the coupled decarboxylase assay of Waymire et al. (1971; see Fluharty et al., 1985). Assay conditions were optimized for each brain region by varying incubation time, $\mathrm{pH}$ of the mixture, and cofactor concentration (Table 1). Tissue was homogenized in $50 \mathrm{~mm}$ Tris- $\mathrm{HCl}$ buffer ( $\mathrm{pH}, 6.0$ ) containing $25 \mathrm{~mm}$ sodium fluoride (to inhibit phosphatases) and centrifuged at $39,000 \times \mathrm{g}$ for $30 \mathrm{~min}$, and an aliquot of the supernatant was assayed in triplicate. Samples were incubated at $37^{\circ} \mathrm{C}$ for 5-15 min in $0.12 \mathrm{M}$ Tris-acetate buffer $(\mathrm{pH}, 5.7-6.2)$ in the presence of $75 \mu \mathrm{M} \mathrm{L}-\left(l-{ }^{14} \mathrm{C}\right)$-tyrosine, $3.0 \mathrm{mM}$ 6-methyl-5,6,7,8-tetrahydropterin $\mathrm{HCl}\left(6 \mathrm{MPH}_{4}\right)$, or $2.5 \mathrm{~mm}$ tetrahydrobiopterin $\left(\mathrm{BH}_{4}\right)$, catalase $(20 \mathrm{mg} / \mathrm{ml})$, and ascorbic acid. The resulting $\left(l-{ }^{-14} \mathrm{C}\right)$-dihydroxyphenylalanine (DOPA) was subsequently decarboxylated by addition of a solution containing excess aromatic amino acid decarboxylase (partially purified 
Figure 2. The effect of acute tail shock on extracellular NE in naive and chronically cold-stressed rats. Thirty minutes of intermittent tail shock (line) was administered after obtaining at least four stable baseline samples. Basal NE levels did not differ between the two groups. duced a $54 \%$ increase in extracellular NE $(n=9)$, while in chronically coldstressed rats (hatched bars), an $82 \%$ increase above baseline occurred $(n=9)$. Results are expressed as mean \pm SEM; $*, p<0.05$ versus respective baseline; ,$+ p<0.05$ chronically cold-stressed versus naive rats. In naive rats (solid bars), tail shock pro-

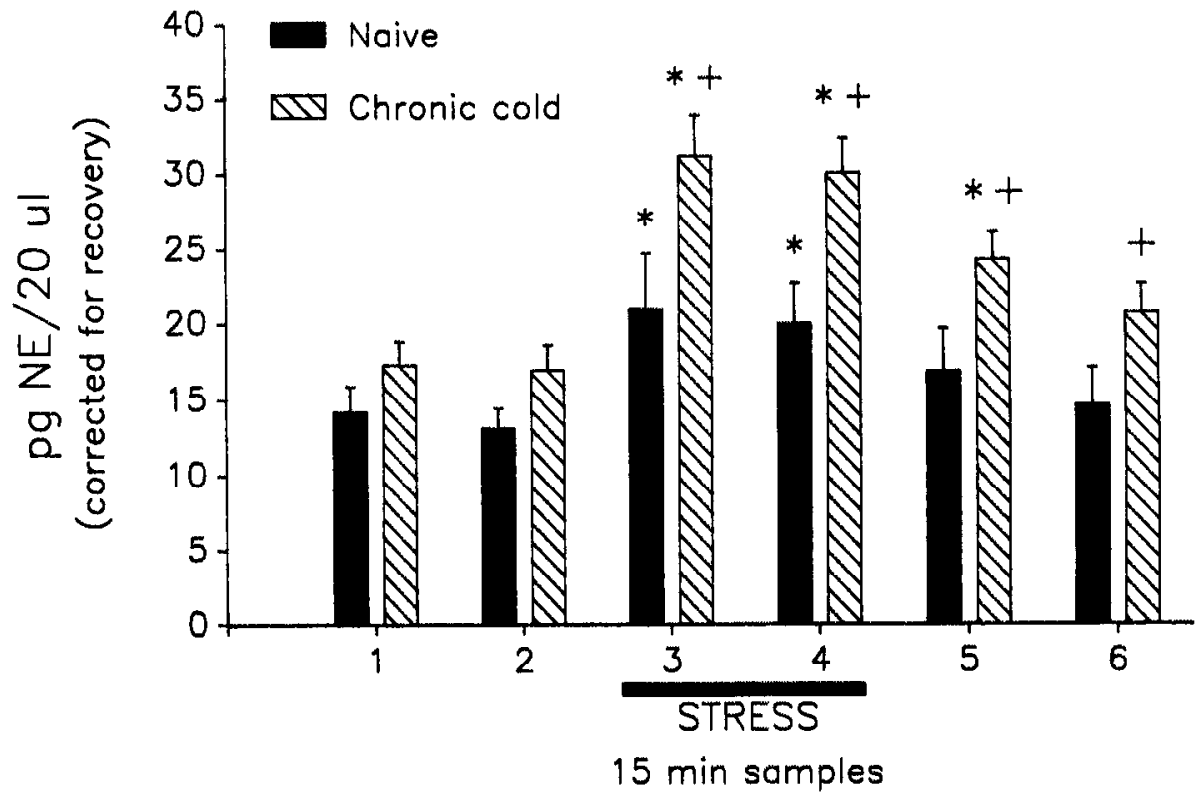

from hog kidney), $0.1 \mathrm{~m}$ Tris-acetate buffer $(\mathrm{pH}, 7.3-7.5$; selected to bring the final $\mathrm{pH}$ of the reaction mixture to 6.8 ), pyridoxal- 5 '-phosphate, and 3-iodo-L-tyrosine to inhibit further hydroxylation. Finally, ${ }^{14} \mathrm{CO}_{2}$ was trapped in TS-1 tissue solubilizer (Research Products International Corp.) and quantified using liquid scintillation spectrometry. Using this procedure, the direct decarboxylation of ${ }^{14} \mathrm{C}$-tyrosine appeared to be minimal because the formation of ${ }^{14} \mathrm{CO}_{2}$ was reduced by $99 \%$ by deletion of cofactor from the mix or by addition of $10 \mathrm{mM}$ 3-iodo-L-tyrosine, an inhibitor of TH activity, to the first incubation mixture. In these experiments, TH activity was assayed under conditions of saturating $6 \mathrm{MPH}_{4}$ or $\mathrm{BH}_{4}$ and optimal $\mathrm{pH}$ and thus reflected maximal velocity of the enzyme (Acheson and Zigmond, 1981). The data were expressed as percent of control in order to facilitate comparison between $\mathrm{LC}$, hippocampal, and adrenal tissues.

\section{DOPA accumulation in hippocampus}

The rate of tyrosine hydroxylation in hippocampus was assayed by measuring the amount of DOPA accumulation in tissue following administration of 3-hydroxybenzylhydrazine dihydrochloride (NSD-1015; Aldrich Chemical Company, Inc.), an inhibitor of aromatic amino acid decarboxylase (Carlsson et al., 1972). Rats were injected with NSD$1015(100 \mathrm{mg} / \mathrm{kg}$, i.p.) and decapitated $30 \mathrm{~min}$ later. The brain was removed rapidly, and hippocampus was dissected out bilaterally. The tissue was frozen immediately on dry ice and was stored at $-70^{\circ} \mathrm{C}$ until assay. Hippocampal tissues were homogenized in $0.1 \mathrm{~N}$ perchloric acid and $0.2 \mathrm{~mm}$ sodium bisulfite, centrifuged twice at 39,000 $\times \mathrm{g}$ for 15 $\mathrm{min}$, and then passed through a $0.45-\mu \mathrm{m}$ filter (Millipore). Samples were then assayed on an HPLC system as previously described (Sved, 1989, 1990). This system was composed of a Waters model M-45 pump, a Waters WISP model 712 automatic sample injector, and a 25-cm Dynamax $5-\mu \mathrm{m}$ C18 column (Rainin). The mobile phase consisted of 100 mм citric acid buffer (pH, 2.78), 100 mм EDTA, 0.32 mm sodium octylsulfate, $4 \%$ acetonitrile, and $0.06 \%$ diethylamine. The flow rate was 1.0 $\mathrm{ml} / \mathrm{min}$. The detection system was an ESA 5100A electrochemical detector with the applied potential of the first electrode set at $+0.20 \mathrm{~V}$

Table 1. TH assay conditions used for adrenal, $\mathrm{LC}$, and hippocampus

\begin{tabular}{lccl} 
& $\begin{array}{c}\text { Incubation } \\
\text { time }(\mathrm{min})\end{array}$ & $\mathrm{pH}$ & $\begin{array}{l}\text { Cofactor } \\
\text { concentration }\end{array}$ \\
\hline Adrenal & 5 & 5.7 & $3.06 \mathrm{MPH}_{4}$ \\
LC & 10 & 6.2 & $3.06 \mathrm{MPH}_{4}$ \\
Hippocampus & 15 & 6.2 & $2.5 \mathrm{BH}_{4}$ \\
\hline
\end{tabular}

and the second electrode set at $-0.20 \mathrm{~V}$. The sensitivity of this assay is about $2.5 \mathrm{pg}$. The rate of accumulation of DOPA in control rats was linear for $30 \mathrm{~min}$. Data are expressed as ng DOPA/gm wet-weight of tissue.

\section{Statistical analysis}

The data are expressed as mean \pm SEM. The effects of tail shock on extracellular levels of NE and DOPAC in hippocampus of naive and chronically cold-stressed rats were analyzed using two-way analysis of variance with repeated measures on one variable coupled with Dunn's post hoc test. DOPA accumulation in naive and chronically stressed rats was analyzed by a two-way analysis of variance. Results for the TH activity measures were analyzed by one-way analysis of variance coupled with Neuman-Keuls post hoc comparisons. The level of significance for all analyses was set at $p<0.05$.

\section{Results}

\section{$N E$ and DOPAC in dialysates from naive and chronically stressed rats}

The basal level of $\mathrm{NE}$ in dialysate from hippocampus of control rats was $13.5 \pm 1.5 \mathrm{pg} / 20 \mu \mathrm{l}(n=9 ;$ Fig. 2$)$. In chronically coldstressed rats $(n=9)$, the basal value of $16.5 \pm 1.6 \mathrm{pg} / 20 \mu \mathrm{l}$ was not significantly different from that observed in control rats. Thirty minutes of intermittent tail-shock stress resulted in a significant increase of NE in dialysates from both control and chronically cold-stressed subjects $[F(5,80)=31.10 ; p<0.01]$. In control rats, a $54 \%$ increase of NE in dialysate occurred, while an $82 \%$ elevation was observed in the chronically coldstressed rats. The tail-shock-induced increase of NE in dialysate from chronically cold-stressed rats was significantly greater than that observed in controls during all of the stress and poststress samples [Fig. 2; $F(5,80)=3.17 ; p<0.05$ ].

The resting level of DOPAC in dialysates from control and chronically cold-stressed rats was equivalent $(35 \pm 4.0 \mathrm{pg} / 20$ $\mu \mathrm{l}, n=9$ vs. $35 \pm 3.0 \mathrm{pg} / 20 \mu \mathrm{l}, n=8$; Fig. 3). In both groups of rats, 30 min of intermittent tail shock resulted in a gradual and prolonged increase in the level of DOPAC in the dialysates $[F(5,75)=31.45 ; p<0.01]$. In control rats, DOPAC increased to $75 \%$ above baseline, while in chronically cold-stressed rats DOPAC levels rose to $136 \%$ above baseline. The tail-shockinduced increase of DOPAC in chronically cold-stressed rats 


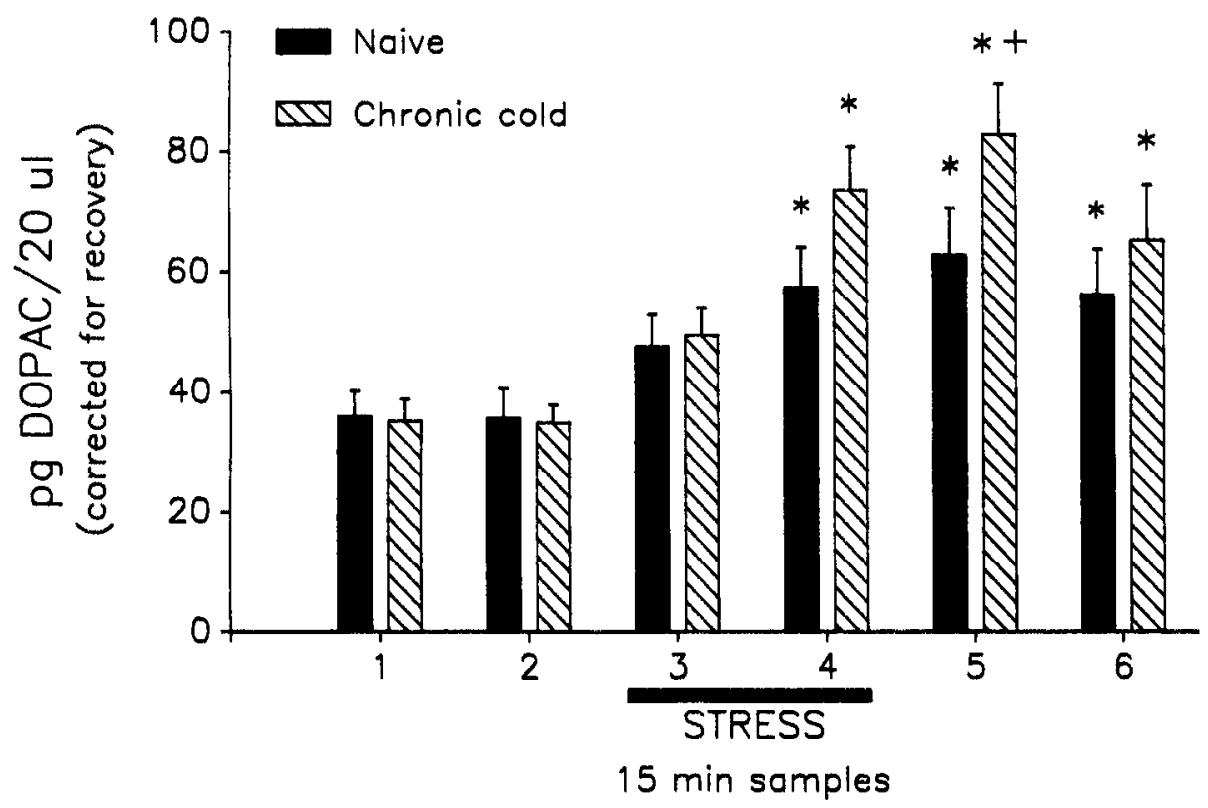

Figure 3. The effect of acute tail shock on extracellular DOPAC in naive and chronically cold-stressed rats. Experimental procedure was as in Figure 2. Basal DOPAC levels did not differ between the two groups. In naive rats (solid bars), tail shock produced a $75 \%$ increase in extracellular DOPAC $(n=9)$, while in chronically cold-stressed rats (hatched bars), a 136\% increase above baseline occurred $(n=8)$. ${ }^{*}, p<0.05$ versus respective baseline;,$+ p<0.05$ chronically cold-stressed versus naive rats. Error bars represent SEM. was significantly greater than that of control rats $[F(5,75)=$ $2.57 ; p<0.05]$.

\section{TH activity in naive and chronically stressed rats}

TH activity was measured in LC, hippocampus, and adrenal glands of rats placed in a cold room for varying durations (Fig. 4). $\mathrm{TH}$ activity, as measured in the presence of a saturating concentration of cofactor, increased by $75 \%$ in LC following 3 $\mathrm{d}$ of cold exposure, declined to $50 \%$ above control by $7 \mathrm{~d}$, and was no longer significantly different from control after $14 \mathrm{~d}$ of cold stress $[F(4,34)=8.29 ; p<0.01]$. In contrast, no significant difference in TH activity was detected in hippocampus of coldexposed rats $[F(3,55)=0.96 ; p>0.05]$. In adrenal gland, TH activity was increased by $104 \%$ following $3 \mathrm{~d}$ of cold exposure, continued to rise to $180 \%$ above control after $7 \mathrm{~d}$, returned to $107 \%$ above baseline by $14 \mathrm{~d}$, and remained significantly elevated for at least $21 \mathrm{~d}[F(4,39)=14.62 ; p<0.01]$.

\section{DOPA accumulation in hippocampus of naive and chronically stressed rats}

Accumulation of DOPA in hippocampal tissue after inhibition of aromatic amino acid decarboxylase activity was measured in naive rats and rats exposed to $21 \mathrm{~d}$ of cold. In the absence of NSD-1015, the endogenous level of DOPA was equivalent in hippocampus of both groups of rats $(7.5+0.9$ vs. $7.1+1.9 \mathrm{ng}$ DOPA/gm tissue for naive and chronic stress, respectively).

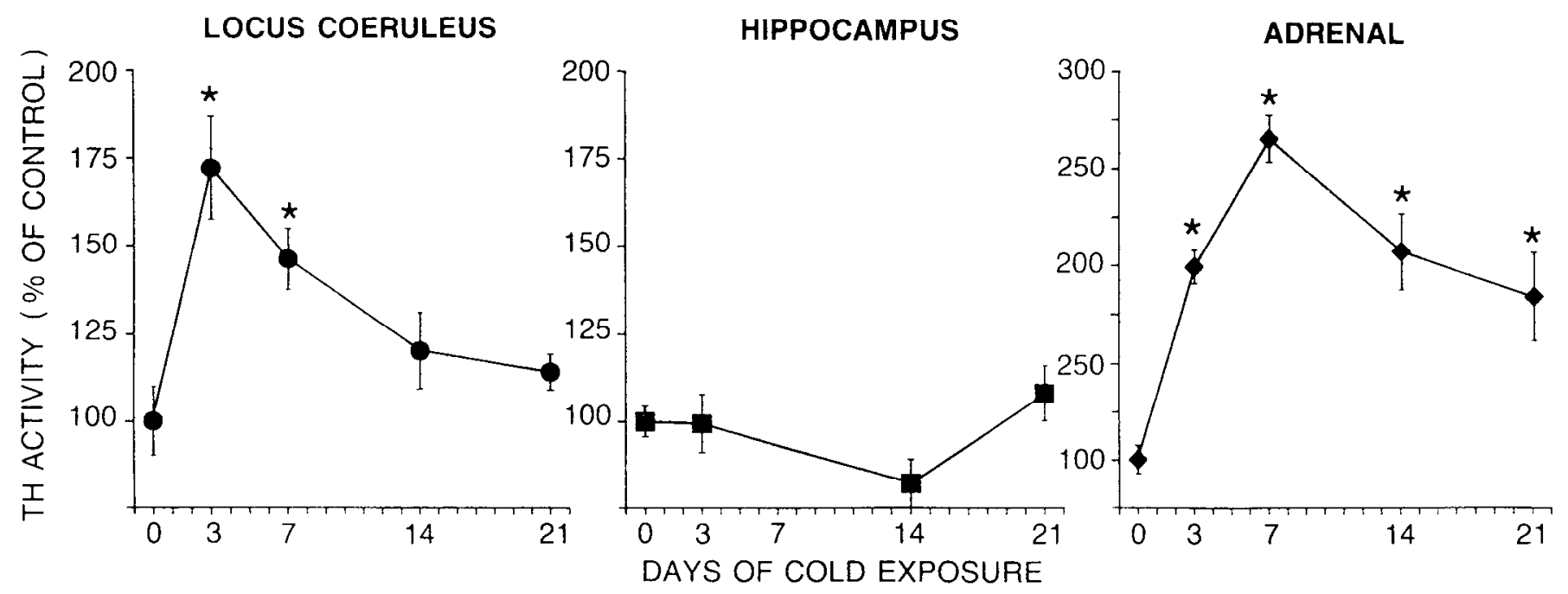

Figure 4. The effect of chronic cold stress on maximal TH activity in LC, hippocampus, and adrenal gland. TH activity in LC (O; $n=6-9$ per group) reached a peak increase of $75 \%$ above control following $3 \mathrm{~d}$ of cold exposure. No significant change was detected in hippocampus $(\pi ; n=$ $6-10$ per group) at any time. In adrenal gland $(\diamond ; n=6-10$ per group), TH activity increased to $180 \%$ above control following $7 \mathrm{~d}$ of cold exposure and then stabilized at about $100 \%$ above control for the duration of the cold stress. Note the difference in scale between LC and hippocampus versus adrenal gland. Control levels of TH activity: LC, $34.4 \pm 3.38 \mathrm{pmol} / \mathrm{min} /$ pair; hippocampus, $6.66 \pm 0.63 \mathrm{pmol} / \mathrm{min} / \mathrm{mg} \mathrm{protein}$; adrenal, $2.05 \pm 0.16 \mathrm{nmol} / \mathrm{min} / \mathrm{gland}$. ${ }^{*}, p<0.05$. Error bars represent SEM. 


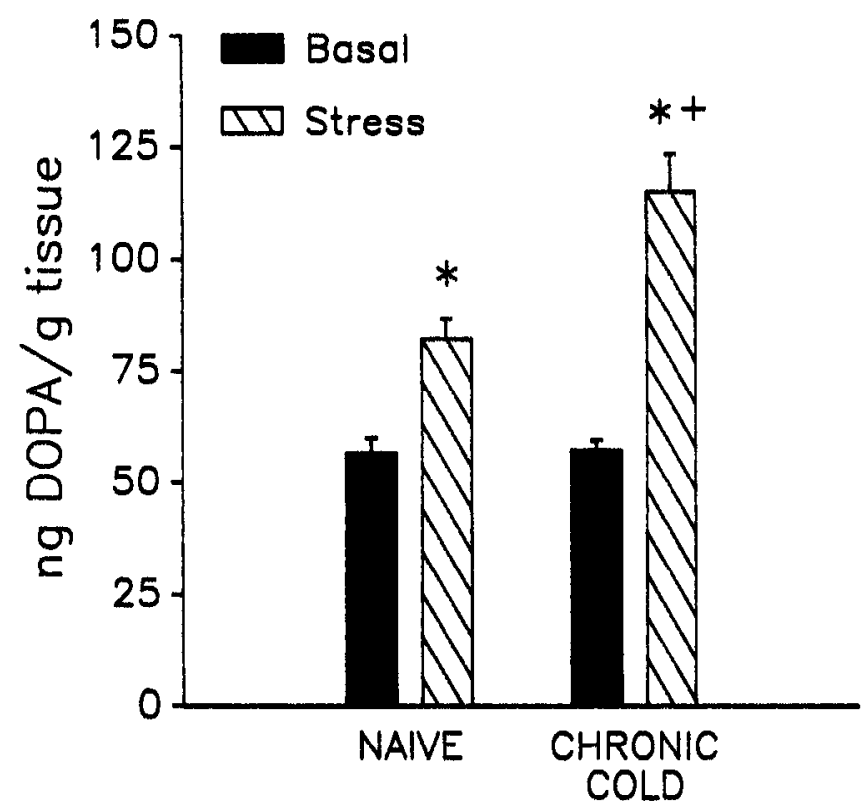

Figure 5. DOPA accumulation in hippocampus of naive and chronically cold-stressed rats subjected to $30 \mathrm{~min}$ of intermittent tail shock. Rats were injected with NSD-1015 (100 mg/kg, i.p.) and either placed back in their home cages for $30 \mathrm{~min}$ or exposed to $30 \mathrm{~min}$ of intermittent tail shock. All rats were then immediately decapitated, and hippocampus was dissected out. Basal accumulation of DOPA did not differ between naive and chronically cold-stressed rats (naive, $56.7 \mathrm{ng}$ DOPA gm tissue, $n=10$; chronically cold-stressed, $57.3 \pm 2.4 \mathrm{ng} \mathrm{DOPA} / \mathrm{gm}$ tissue, $n=5$ ). Following $30 \mathrm{~min}$ of intermittent tail shock, DOPA accumulation increased to a significantly greater level in the chronically cold-stressed rats $(101 \% ; n=12)$ than in the naive rats $(45 \% ; n=10)$. ${ }^{*}, p<0.05$ versus basal;,$+ p<0.05$ chronically cold-stressed versus naive rats. Error bars represent SEM.

Under basal conditions, DOPA accumulation following administration of NSD-1015 was similar in naive and chronically stressed rats $(56.7 \pm 3.4$ vs. $57.3 \pm 2.4 \mathrm{ng}$ DOPA/gm tissue; Fig. 5). In response to tail-shock stress, DOPA accumulation increased $45 \%$ in naive rats, whereas a $101 \%$ elevation occurred in the chronically stressed rats. This acute stress-induced increase in DOPA accumulation was significantly greater in the chronically cold-stressed rats than in controls $[F(1,33)=40.2$; $p<0.0001]$.

\section{Discussion}

The present data provide the first direct demonstration of enhanced stress-induced NE efflux in brain resulting from previous exposure to chronic stress. Specifically, we have used in vivo microdialysis to study changes in the extracellular level of NE in the dentate gyrus region of hippocampus. Naive rats and rats previously exposed to $3-4$ weeks of cold were subjected to an acute tail-shock paradigm. In agreement with our previous findings (Abercrombie et al., 1988), 30 min of intermittent tail shock was found to increase extracellular NE in hippocampus of naive rats. However, whereas the basal level of extracellular NE in naive and chronically stressed rats was similar, the tail-shockinduced increase in extracellular NE was significantly greater in the latter group. To the extent that NE measured in the dialysate is a reflection of released neurotransmitter, the results suggest that stress-induced NE release is increased to a greater degree in hippocampus of chronically cold-stressed rats than in controls.
Chronic stress previously has been shown to result in a downregulation of $\beta$-adrenergic receptors as well as a decrease in the sensitivity of adenylate cyclase to catecholamines (Stone and Platt, 1982; Stone et al., 1985). It has been hypothesized that this subsensitivity may contribute to behavioral adaptation of the rat to chronic stress (Stone, 1987; Anisman and Zacharko, 1990). Assuming that a similar decrease in sensitivity occurs under the present conditions of chronic stress, the postsynaptic impact of a given level of NE release would be decreased. If a rat that has adapted to chronic stress is presented with a novel stressor, however, it might be advantageous to increase the overall signaling of the LC system to a level similar to that of a naive rat. Under these circumstances, it would be necessary to release more NE to achieve the desired postsynaptic effect. Therefore, the enhanced noradrenergic response in the previously stressed rat may allow it to respond to a behaviorally relevant stimulus to the same degree as a naive rat. Under conditions of severe chronic stress, however, it is possible that the observed alterations in the regulation of the noradrenergic system may become maladaptive to the organism (Weiss and Simson, 1986). In this case, the enhanced noradrenergic activation in chronically stressed rats could prove to be a precipitating factor in stressinduced behavioral disorders such as clinical anxiety and depression (Post and Weiss, 1988).

There exists a great deal of evidence suggesting that neurotransmitter synthesis is coupled to release (for review, see Zigmond et al., 1989; Fillenz, 1990). Therefore, one factor that might contribute to the enhanced release of NE observed in the present study is an increase in NE biosynthesis. In order to examine this possibility, we employed several techniques to investigate the effect of chronic stress on NE biosynthesis. The first method allowed an indirect measure of NE synthesis to be obtained in vivo. As can be seen in Figure 1, a small amount of DOPAC was present in the hippocampal dialysates. Because no significant dopaminergic innervation of the dorsal dentate gyrus appears to exist (Verney et al., 1985), DOPAC probably is produced in NE terminals by metabolism of the NE precursor dopamine. Thus, the DOPAC we are measuring presumably is derived during the process of conversion of dopamine to $\mathrm{NE}$ in the noradrenergic nerve terminal. Extracellular DOPAC in the dentate gyrus may therefore reflect the balance between dopamine synthesis and transport into NE storage vesicles within the NE terminals (see Abercrombie and Zigmond, 1989).

The basal level of extracellular DOPAC measured in control and chronically stressed rats was the same, suggesting that under resting conditions neurotransmitter synthesis was similar in both groups of rats. These data are compatible with the finding that the basal extracellular NE concentration in control and chronically stressed rats did not differ. In response to acute tail shock, there was an elevation in extracellular DOPAC in all rats, indicating an increase in NE synthesis. This result is consistent with previous studies demonstrating that increased neuronal activity, elicited by direct electrical stimulation or presentation of stressful stimuli, produces a short-term activation of TH in NE neurons (Salzman and Roth, 1980; Iuvone and Dunn, 1986). Furthermore, the stress-induced increase in DOPAC observed in our experiments was greater in rats exposed to chronic cold than in controls, suggesting that a larger increase in NE synthesis occurred in the chronically stressed rats.

In order to investigate more directly the changes in NE biosynthesis, two other measures also were employed. The first series of experiments used an in vitro assay of the activity of 
TH. By assaying under conditions of saturating cofactor and optimal $\mathrm{pH}$, the maximal biosynthetic capacity of the neurons was determined (see Acheson and Zigmond, 1981). In agreement with earlier studies (Zigmond et al., 1974; Stachowiak et al., 1986; Richard et al., 1988), chronic cold exposure resulted in an increase in TH activity in the LC cell body region. A more detailed examination of the cold-induced changes in $\mathrm{TH}$ activity demonstrated that TH activity in LC began to decline within 7 $\mathrm{d}$ of the onset of cold stress and was no longer significantly different following $14 \mathrm{~d}$ of cold exposure.

Previous investigations of both central and peripheral catecholaminergic neurons have shown that an increase in cell body TH activity can be followed several days to weeks later by an elevation in terminal-region TH activity (Black, 1975; Zigmond, 1979; Acheson and Zigmond, 1981). In order to determine whether such a change occurred in hippocampus following chronic stress, TH activity was measured in this region 3,14 , and $21 \mathrm{~d}$ after the initiation of cold exposure. At these times, however, no significant alterations in TH activity were observed. One potential reason for the lack of a detectable change in hippocampal TH activity following cold exposure is that the rats had habituated to the chronic stressor. This could also explain the return of TH activity in LC to control levels after $14 \mathrm{~d}$ of cold exposure. In contrast, adrenal TH activity remained elevated even at times when LC and hippocampal TH activity did not differ from control, suggesting that the rats had not completely habituated to the cold. However, it is also possible that the elevation in adrenal $\mathrm{TH}$ activity underlies the mechanism by which the rat adapts to the cold. Thus, if the sympathoadrenal response alleviates the stressful nature of the stimulus, the LC system may no longer be activated.

Another possible explanation for the lack of any measurable elevation in hippocampal TH activity is suggested by a previous study examining reserpine-induced changes in $\mathrm{TH}$ activity within LC cell body and terminal regions (Zigmond, 1979). In that study, a $300 \%$ elevation in TH activity in the LC cell body region occurred within $3 \mathrm{~d}$ of the reserpine injection. In hippocampus, the peak elevation of TH activity was delayed until $21 \mathrm{~d}$ after reserpine administration and only reached $90 \%$ above control levels. Fxtrapolating from these data, the $75 \%$ elevation in TH activity in LC following chronic cold stress observed in the present study would lead to only a $25 \%$ increase in hippocampal TH activity about $21 \mathrm{~d}$ after the initiation of the cold exposure. Using the current activity assay, this change would fall within the interanimal variability. Thus, while our data suggest that no increase in maximal TH activity occurred following chronic cold stress, the possibility exists that available analytical methods are not sensitive enough to detect any small changes that might have occurred.

In the second series of experiments designed to investigate changes in NE biosynthesis in acute and chronically stressed rats, an in vivo measurement of tyrosine hydroxylation was utilized (Carlsson et al., 1972). This technique determines the ongoing synthetic rate of NE by measuring the accumulation of the product of tyrosine hydroxylation, DOPA, in tissue following the blockade of its metabolism. These studies indicated that the basal synthetic rate of NE in hippocampus of chronically stressed rats was not different from that of naive rats. In response to tail-shock stress, however, DOPA accumulation was elevated to a greater extent in rats previously exposed to chronic cold stress than in controls. These results are consistent with the results reported for extracellular DOPAC obtained using mi- crodialysis (see above). Taken together, these data suggest that under basal conditions NE synthesis is equivalent in both groups, but that in response to a novel stressor, there is a greater elevation of NE biosynthesis in the chronically stressed rats.

In summary, the present data demonstrate directly that prior exposure to chronic stress results in enhanced hippocampal NE release in response to a novel stressor. In addition, an increased rate of NE synthesis is evident in the chronically stressed rats when challenged with a novel stressor. We hypothesize that this enhanced noradrenergic activation normally may ensure adequate postsynaptic stimulation in response to a novel stressor in an organism that has adapted to a chronic stress. However, under conditions of severe and/or prolonged stress, it is possible that the observed changes in the noradrenergic system could become maladaptive and thus potentially contribute to stressinduced behavioral disorders.

\section{References}

Abercrombie ED, Jacobs BL (1987) Single-unit response of noradrenergic neurons in the locus coeruleus of freely moving cats. I. Acutely presented stressful and nonstressful stimuli. J Neurosci 7:28372843.

Abercrombie ED, Zigmond MJ (1989) Partial injury to central noradrenergic neurons: reduction of tissue norepinephrine content is greater than reduction of extracellular norepinephrine measured by microdialysis. J Neurosci 9:4062-4067.

Abercrombie ED, Keller RW, Zigmond MJ (1988) Characterization of hippocampal norepinephrine release as measured by microdialysis perfusion: pharmacological and behavioral studies. Neuroscience 27: 897-904.

Abercrombie ED, Keefe KA, DiFrischia DS, Zigmond MJ (1989) Differential effect of stress on in vivo dopamine release in striatum, nucleus accumbens, and medial frontal cortex. J Neurochem 52:16551658.

Acheson AL, Zigmond MJ (1981) Short and long term changes in tyrosine hydroxylase activity in rat brain after subtotal destruction of central noradrenergic neurons. J Neurosci 1:493-504.

Adell A, Garcia-Marquez C, Armario A, Gelpi E (1988) Chronic stress increases serotonin and noradrenaline in rat brain and sensitizes their responses to a further acute stress. J Neurochem 50:1678-1681.

Anisman H, Zacharko RM (1990) Multiple neurochemical and behavioral consequences of stressors: implications for depression. Pharmacol Ther 46:119-136.

Badoer E, Wurth H, Turck D, Qadri F, Itoi K, Dominiak P, Unger TH (1989) The $\mathrm{K}^{+}$-induced increases in noradrenaline and dopamine release are accompanied by reductions in the release of their intraneuronal metabolites from the rat anterior hypothalamus: an in vivo brain microdialysis study. Naunyn Schmiedebergs Arch Pharmacol 339:54-59.

Black IB (1975) Increased tyrosine hydroxylase activity in frontal cortex and cerebellum after reserpine. Brain Res 95:170-176.

Carlsson A, Davis JN, Kehr W, Lindqvist M, Atack CV (1972) Simultaneous measurement of tyrosine and tryptophan activities in brain in vivo using an inhibitor of the aromatic amino acid decarboxylase. Naunyn Schmiedebergs Arch Pharmacol 275:153-168.

Chuang D, Costa E (1974) Biosynthesis of tyrosine hydroxylase in rat adrenal medulla after exposure to cold. Proc Natl Acad Sci USA 71: $4570-4574$.

Fillenz M (1990) Regulation of catecholamine synthesis: multiple mechanisms and their significance. Neurochem Int 17:303-320.

Fluharty SJ, Snyder GL, Stricker EM, Zigmond MJ (1983) Short- and long-term changes in adrenal tyrosine hydroxylase activity during insulin-induced hypoglycemia and cold stress. Brain Res 267:384387.

Fluharty SJ, Snyder GL, Zigmond MJ, Stricker EM (1985) Tyrosine hydroxylase activity and catecholamine biosynthesis in the adrenal medulla of rats during stress. J Pharmacol Exp Ther 233:32-38.

Glavin GB, Tanaka M, Tsuda A, Kohno Y, Hoaki Y, Nagasaki N (1983) Regional rat brain noradrenaline turnover in response to restraint stress. Pharmacol Biochem Behav 19:287-290.

Irwin J, Ahluwalia P, Anisman H (1986) Sensitization of norepi- 
nephrine activity following acute and chronic footshock. Brain Res 379:98-103.

Iuvone PM, Dunn AJ (1986) Tyrosine hydroxylase activation in mesocortical 3,4-dihydroxyphenylethylamine neurons following footshock. J Neurochem 47:837-844.

Joh TH, Gregham C, Reis D (1973) Immunochemical demonstration of increased accumulation of tyrosine hydroxylase protein in sympathetic ganglia and adrenal medulla elicited by reserpine. Proc Natl Acad Sci USA 70:2767-2771.

Kalen P, Rosegren E, Lindvall O, Bjorklund A (1989) Hippocampal noradrenaline and serotonin release over 24 hours as measured by the dialysis tcchnique in frecly moving rats: correlation to behavioural activity state, effect of handling and tail-pinch. Eur J Neurosci 1:181188.

Korf J, Aghajanian GK, Roth RH (1973) Increased turnover of norepinephrine in the rat cerebral cortex during stress: role of the locus coeruleus. Neuropharmacology 12:933-938.

Kvetnansky R, Nemeth S, Vigas M, Oprsalova Z, Jurcovicova J (1983) Plasma catecholamines in rats during adaptation to intermittent exposure to different stressors. In: Stress: the role of catecholamines and other neurotransmitters, Vol 1 (Usdin E, Kvetnansky R, Axelrod J, eds), pp 537-562. New York: Gordon and Breach.

Maynert EW, Levi R (1964) Stress-induced release of brain norepinephrine and its inhibition by drugs. J Pharmacol Exp Ther 143:9095.

Post RM, Weiss SRB (1988) Scnsitization and kindling: implications for the evolution of psychiatric symptomatology. In: Sensitization in the nervous system (Kalivas PW, Barnes CD, eds), pp 257-291. Caldwell, NJ: Telford.

Richard F, Faucon-Biguet N, Labautu R, Rollet D, Mallet J, Buda M (1988) Modulation of tyrosine hydroxylase gene expression in rat brain and adrenals by exposure to cold. J Neurosci Res 20:32-37.

Ritter S, Ritter RC (1977) Protection against stress-induced brain norepinephrine depletion after repeated 2-deoxy-D-glucose administration. Brain Res 127:179-184.

Salzman PM, Roth RH (1980) Poststimulation catecholamine synthesis and tyrosine hydroxylase activation in central noradrenergic neurons. I. In vivo stimulation of the locus coeruleus. J Pharmacol Exp Ther 212:64-73.

Stachowiak MK, Fluharty SJ, Stricker EM, Zigmond MJ, Kaplan BB (1986) Molecular adaptations in catecholamine biosynthesis induced by cold stress and sympathectomy. J Neurosci Res 16:13-24.

Stone EA (1987) Central cyclic-AMP-linked noradrenergic receptors: new findings on properties as related to the actions of stress. Neurosci Biobehav Rev 11:391-398.

Stone EA, Platt JE (1982) Brain adrenergic receptors and resistance to stress. Brain Res 237:405-414.

Stone EA, Freedman LS, Morgano LE (1978) Brain and adrenal tyrosine hydroxylase activity after chronic footshock stress. Pharmacol Biochem Behav 9:551-553.

Stone EA, Slucky AV, Platt JE, Trullas R (1985) Reduction of the cyclic adenosine $3^{\prime}, 5^{\prime}$-monophosphate response to catecholamines in rat brain slices after repeated restraint stress. J Pharmacol Exp Ther 233:382-388.

Sved AF (1989) PNMT-containing catecholaminergic neurons are not necessarily adrenergic. Brain Res 481:113-118.

Sved AF (1990) Effect of monoamine oxidase inhibition on catecholamine levels: evidence for synthesis but not storage of epinephrine in rat spinal cord. Brain Res 512:253-258.

Tanaka M, Kohno Y, Nakagawa R, Ida Y, Takeda S, Nagasaki N, Noda N (1983) Regional characteristics of stress-induced increases in brain noradrenaline release in rats. Pharmacol Biochem Behav 19:543-547.

Thierry AM, Javoy J, Glowinski J, Kety SS (1968) Effects of stress on the metabolism of norepinephrine, dopamine and serotonin in the central nervous system of the rat. I. Modifications of norepinephrine turnover. J Pharmacol Exp Ther 163:163-171.

Thoenen $H$ (1970) Induction of tyrosine hydroxylase in peripheral and central adrenergic neurones by cold-exposure of rats. Nature 228 : 861-862.

Tsuda A, Tanaka M, Kohno Y, Nishikawa T, Iimori K, Nakagawa R, Hoaki Y, Ida Y, Nagasaki N (1982) Marked enhancement of noradrenaline turnover in extensive brain regions after activity-stress in rats. Physiol Behav 29:337-341.

Verney C, Baulac M, Berger B, Alvarez C., Vigny A, Helle KB (1985) Morphological evidence for a dopaminergic terminal field in the hippocampal formation of young and adult rat. Neuroscience 14:10391052.

Waymire JC, Bjur R, Weiner N (1971) Assay of tyrosine hydroxylase by coupled decarboxylation of dopa formed from $l^{-14} \mathrm{C}-\mathrm{L}$-tyrosine. Anal Biochem 43:588-600.

Weiss JM, Simson PE (1986) Neurochemical and electrophysiological events underlying stress-induced depression in an animal model. In: Mechanisms of physical and emotional stress (Chrousos GP, Loriaux DL, Gold PW, eds), pp 425-440. New York: Plenum.

Weiss JM, Glazer HI, Pohorecky LA (1976) Coping behavior and neurochemical changes: an alternative explanation for the original "learned helplessness" experiments. In: Animal models in human psychobiology (Serban G, Kling A, eds), pp 141-173. New York: Plenum.

Zigmond MJ, Harvey JA (1970) Resistance to central norepinephrine depletion and decreased mortality in rats chronically exposed to electric foot shock. J Neurovisc Rel 31:373-381.

Zigmond RE (1979) Tyrosine hydroxylase activity in noradrenergic neurons of the locus coeruleus after reserpine administration: sequential increase in cell bodies and nerve terminals. J Neurochem 32:23-29.

Zigmond RE, Schon F, Iversen LL (1974) Increased tyrosine hydroxylase activity in the locus coeruleus of rat brain stem after reserpine treatment and cold stress. Brain Res 70:547-552.

Zigmond RE, Schwarzschild MA, Rittenhouse AR (1989) Acute regulation of tyrosine hydroxylase by nerve activity and by neurotransmitters via phosphorylation. Annu Rev Neurosci 12:415-461. 